\title{
Transcatheter aortic valve replacement for isolated aortic regurgitation is coming!
}

\author{
Jian Ye, MD
}

\footnotetext{
From the Division of Cardiac Surgery, St Paul's Hospital, University of British Columbia, Vancouver, British Columbia, Canada.

Disclosures: J.Y. is a consultant to JC Medical Inc.

Received for publication March 4, 2018; accepted for publication March 9, 2018; available ahead of print April 5, 2018.

Address for reprints: Jian Ye, MD, Division of Cardiac Surgery, St Paul's Hospital, 1081 Burrard St, Vancouver V6Z 1Y6, British Columbia, Canada (E-mail: jye@ providencehealth.bc.ca).

J Thorac Cardiovasc Surg 2018;156:117-8

$0022-5223 / \$ 36.00$

Copyright (c) 2018 by The American Association for Thoracic Surgery

https://doi.org/10.1016/j.jtcvs.2018.03.038
}

Off-label uses of currently available transcatheter heart valves (THVs) have been expanded to patients with isolated aortic regurgitation (AR). ${ }^{1}$ The experience with earlygeneration THVs has been very disappointing, however, with low success rate, frequent malpositioning, and significant paravalvular leak. ${ }^{2}$ The outcome with newer secondgeneration THVs is improving, but it is still not fully acceptable. $^{3}$

In this issue of The Journal of Thoracic and Cardiovascular Surgery, Liu and colleagues ${ }^{4}$ report very good 1year outcomes from the multicenter, prospective study on J-Valve (JC Medical, Inc, Burlingame, Calif) in the treatment of 43 high-risk patients with AR (logistic euroSCORE, $25.5 \% \pm 5.3 \%$ ). The success rate of transapical implantation was high $(97.7 \%)$, with very low 30-day mortality $(2.3 \%)$, transfusion rate $(2.3 \%)$, and pacemaker implantation rate $(2.3 \%)$. More importantly, there were no strokes within 30 days, and no second valve implantations were required. These early outcomes with J-Valve are very encouraging and superior to those with other THVs reported by Yoon and associates. ${ }^{3}$ With other new generation THVs, the 30-day mortality was $9.4 \%$, the need for second valve implantation was $12.7 \%$, and the pacemaker implantation rate was $18.6 \%$. The 1 -year outcome is also excellent, with an all-cause mortality of $4.7 \%$, which is much lower than that in the International Registry $(24.1 \%)$ reported by Yoon and associates, ${ }^{3}$ although patient ages were comparable. More impressively, the operators at 3 centers involved in the J-Valve study had no transcatheter aortic valve replacement or transapical experience before this study. I believe that the superior outcomes were attributable not only to the heart teams but also to the unique feature of "autoanatomical positioning" of the J-Valve, as well as the simplicity and reliability of the J-Valve implantation in patients with AR. I have been using the J-Valve for high-risk patients with AR at our center.

Liu and colleagues ${ }^{4}$ deserve big congratulations for their excellent early outcomes, which provide important near future.

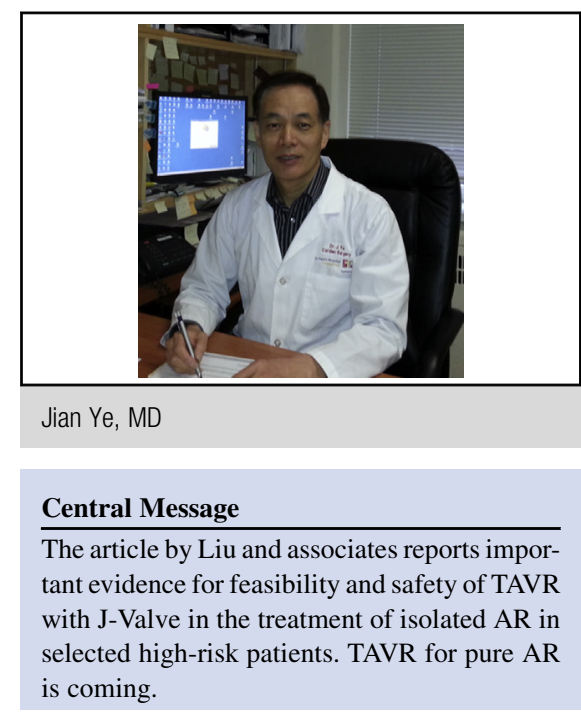

See Article page 106.

evidence of feasibility and safety of transcatheter aortic valve replacement with the J-Valve in the treatment of isolated AR in selected high-risk patients. The number of cases in the study was still relatively small, however, and the duration of the follow-up was also short. More data and randomized trials are clearly required to expand transcatheter aortic valve replacement to moderate risk patients with AR. A few limitations should be noted, and some questions remain to be addressed. A core laboratory was not used for postoperative echocardiographic assessment, and considerable variability could exist among readers at 3 centers. The larger sizes $(29$ and $31 \mathrm{~mm}$ ) of the J-Valve were not available for the study, patients with significantly dilated annulus (>29 mm) were excluded, and undersizing or minimal oversizing occurred in the study, which may be the explanation for the $20.5 \%$ mild paravalvular leak at 1 year. What is optimal oversizing for patients with AR? Does the J-Valve provide long-term stabilization of the annulus-root complex in patients with dilated aortic annulus? With further refinements in patient selection, risk assessment for paravalvular leak, and prosthesis sizing, outcomes with the J-Valve will improve further. More data on the J-Valve are expected because the transapical J-Valve system was approved in 2017 for commercial use in high-risk patients with aortic stenosis or AR. We suspect that the transfemoral J-Valve system will be ready for the first-in-human trial in the 
Surgical aortic valve repair or replacement remains the standard of care for most patients with AR. Transcatheter aortic valve replacement for isolated AR is coming, though, and it will save lives!

\section{References}

1. Hira RS, Vemulapalli S, Li Z, McCabe JM, Rumsfeld JS, Kapadia SR, et al. Trends and outcomes of off-label use of transcatheter aortic valve replacement. Insights from the NCDR STS/ACC TVT registry. JAMA Cardiol. 2017;2:846-54.
2. Franzone A, Piccolo R, Siontis GC, Lanz J, Stortecky S, Praz F, et al Transcatheter aortic valve replacement for the treatment of pure native aortic valve regurgitation: a systematic review. J Am Coll Cardiol Interv. 2016;9:2308-17.

3. Yoon S-H, Schmidt T, Bleiziffer S, Schofer N, Fiorina C, Munoz-Garcia AJ, et al. Transcatheter aortic valve replacement in pure native aortic valve regurgitation. J Am Coll Cardiol. 2017;70:2752-63.

4. Liu H, Yang Y, Wang WS, Zhu D, Wei L, Guo K, et al. Transapical transcatheter aortic valve replacement for aortic regurgitation with a secondgeneration heart valve. J Thorac Cardiovasc Surg. 2018;156:106-16. 